\title{
Acetaminophen-Induced Acute Liver Failure: Results of a United States Multicenter, Prospective Study
}

\author{
Anne M. Larson, ${ }^{1}$ Julie Polson, ${ }^{2}$ Robert J. Fontana, ${ }^{3}$ Timothy J. Davern, ${ }^{4}$ Ezmina Lalani, ${ }^{2}$ Linda S. Hynan, ${ }^{5}$ \\ Joan S. Reisch, ${ }^{5}$ Frank V. Schiødt, ${ }^{2}$ George Ostapowicz, ${ }^{2}$ A. Obaid Shakil, ${ }^{6}$ William M. Lee, ${ }^{2}$ and \\ the Acute Liver Failure Study Group
}

\begin{abstract}
Severe acetaminophen hepatotoxicity frequently leads to acute liver failure (ALF). We determined the incidence, risk factors, and outcomes of acetaminophen-induced ALF at 22 tertiary care centers in the United States. Detailed prospective data were gathered on 662 consecutive patients over a 6-year period fulfilling standard criteria for ALF (coagulopathy and encephalopathy), from which 275 (42\%) were determined to result from acetaminophen liver injury. The annual percentage of acetaminophen-related ALF rose during the study from $28 \%$ in 1998 to $51 \%$ in 2003 . Median dose ingested was $24 \mathrm{~g}$ (equivalent to 48 extra-strength tablets). Unintentional overdoses accounted for 131 (48\%) cases, intentional (suicide attempts) 122 (44\%), and $22(8 \%)$ were of unknown intent. In the unintentional group, 38\% took two or more acetaminophen preparations simultaneously, and $63 \%$ used narcotic-containing compounds. Eighty-one percent of unintentional patients reported taking acetaminophen and/or other analgesics for acute or chronic pain syndromes. Overall, 178 subjects (65\%) survived, $74(27 \%)$ died without transplantation, and 23 subjects $(8 \%)$ underwent liver transplantation; $71 \%$ were alive at 3 weeks. Transplant-free survival rate and rate of liver transplantation were similar between intentional and unintentional groups. In conclusion, acetaminophen hepatotoxicity far exceeds other causes of acute liver failure in the United States. Susceptible patients have concomitant depression, chronic pain, alcohol or narcotic use, and/or take several preparations simultaneously. Education of patients, physicians, and pharmacies to limit high-risk use settings is recommended. (HePATOLOGY 2005;42:1364-1372.)
\end{abstract}

Abbreviations: ALF, acute liver failure. NAC, N-acetylcysteine; ALFSG, Acute Liver Failure Study Group; INR, International Normalized Ratio; ALT, alanine aminotransferase; APACHE, Acute Physiology and Chronic Health Evaluation II; MELD, Model for End-Stage Liver Disease; OTC, over the counter; BMI, body mass index.

From the ${ }^{1}$ Department of Internal Medicine, Division of Gastroenterology, University of Washington Medical Center, Seattle WA; the ${ }^{2}$ Department of Internal Medicine, Division of Digestive and Liver Diseases, University of Texas Southwestern Medical Center, Dallas, TX; the ${ }^{3}$ Department of Internal Medicine, Division of Gastroenterology, University of Michigan, Ann Arbor, MI; the ${ }^{4}$ Department of Internal Medicine, Division of Gastroenterology, University of California at San Francisco, San Francisco, CA; the ${ }^{5}$ Center for Biostatistics and Clinical Science, University of Texas Southwestern Medical Center, Dallas, TX; and the ${ }^{6}$ Department of Medicine, Division of Gastroenterology, University of Pittsburgh Medical Center, Pittsburgh, PA.

Received June 24, 2005; accepted September 12, 2005.

Supported by NIDDK R-01-DK58639 and the Stephen B. Tips Fund at Northwestern University. Supported in part by FDA grant FD-R-001661, NIH grants R-O3 DK52827 and R-01 DK58369, the Stephen B. Tips Fund of Northwestern Medical Foundation, and the Jeanne Roberts Fund of the Southwestern Medical Foundation. F.V.S. received an AASLD/Schering Research Fellowship.

Address reprint requests to: Anne M. Larson, M.D., Assistant Professor of Medicine, University of Washington, Box 356174, Room EE-425, 1959 NE Pacific St., Seattle, WA 98195-6174.E-mail: amlarson@u.washington.edu; fax: 206-598-3884.

Copyright $(2005$ by the American Association for the Study of Liver Diseases.

Published online in Wiley InterScience (www.interscience.wiley.com).

DOI 10.1002/hep.20948

Potential conflict of interest: Nothing to report.
See Editorial on Page 1252.

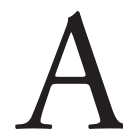
cetaminophen, the most widely used analgesic in the United States, causes severe hepatic necrosis leading to acute liver failure (ALF) after suicidal overdoses. ${ }^{1-3}$ Unintentional liver injury from self-medication for pain or fever that leads to daily doses exceeding the $4 \mathrm{~g} /$ day package recommendations is also well-recognized. ${ }^{4-7}$ Fasting and alcohol use may enhance toxicity, but this remains controversial. ${ }^{6,8} \mathrm{~N}$-acetylcysteine (NAC) can prevent hepatic injury if given within 12 hours of a single ingestion. However, unintentional overdosing is usually only recognized after symptoms have developed. Extended acetaminophen dosing, delay in seeking medical attention, and/or failure to institute NAC therapy are associated with greater morbidity and mortality.9,10 In retrospective studies, poorer outcomes also have been reported for subjects with unintentional acetaminophen overdose, but these data are incomplete. ${ }^{4-7}$

Before the 1980s, acetaminophen was not mentioned as a cause in case series of ALF. ${ }^{11,12}$ A U.S. retrospective study from 1994 to 1996 found a 20\% incidence of acet- 
aminophen toxicity leading to ALF. ${ }^{13}$ In January 1998, we began to examine prospectively the epidemiology and outcomes of all forms of ALF in the United States at the centers participating in the Acute Liver Failure Study Group (ALFSG). In the current study, we investigated the incidence, risk factors, and outcomes of a cohort of 275 consecutive U.S. patients with acetaminophen-related ALF enrolled in the ALFSG registry over 6 calendar years from start of study through December 31, 2003. Based on earlier observations, we hypothesized that patients with unintentional acetaminophen overdose would present with more severe disease [higher international normalized ratio (INR), APACHE score, stage 3 or 4 encephalopathy], more frequently suffer from alcohol abuse, and have a poorer rate of spontaneous transplant-free survival compared with intentional overdose patients. ${ }^{14}$

\section{Patients and Methods}

Between January 1, 1998, and December 31, 2003, demographic, clinical, laboratory, and outcome information were prospectively recorded on all subjects meeting entry criteria for ALF at the 22 academic centers participating in the ALFSG. By definition, eligible patients had an INR $\geq 1.5$, evidence of hepatic encephalopathy, ${ }^{15}$ and presented within 26 weeks of illness onset without apparent chronic liver disease. ${ }^{13}$ Because subjects were encephalopathic (per definition), written informed consent was obtained from their legal next of kin. Data were collected on an admission case report form and subsequently on a separate study outcome form, with outcome defined as liver transplantation, discharge, or 3 weeks after admission. ${ }^{16}$ All centers were in compliance with their local institutional review board requirements. A Certificate of Confidentiality was obtained from the National Institutes for Mental Health for the entire study.

A careful history of acetaminophen ingestion was elicited where possible for each patient, including total dose, type of acetaminophen product taken, and duration of use. Criteria for assigning acetaminophen as the cause of ALF were: (1) a history of potentially toxic acetaminophen ingestion (i.e., $>4 \mathrm{~g} /$ day, the maximum dose recommended on the package) within 7 days of presentation; (2) detection of any level of acetaminophen in the serum; or (3) a serum alanine aminotransferase (ALT) $>1,000$ IU/L with a history of acetaminophen ingestion, irrespective of the acetaminophen level. Exclusion of competing causes of ALF was also required, including acute hepatitis $A$ and $B$, hepatic ischemia, autoimmune hepatitis, and Wilson disease, among other etiologies. ${ }^{16}$ Criteria for listing and proceeding with liver transplantation were those used at each clinical center. Case report forms were re-

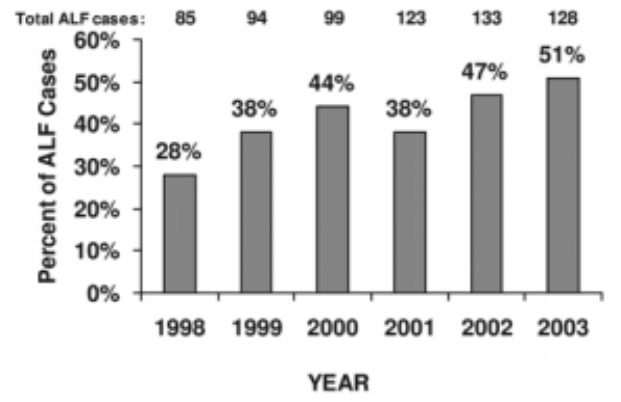

Fig. 1. Proportion of ALF cases attributed to acetaminophen in each of the first 6 years of the ALF Study Group: January 1998 to December 2003.

viewed by investigators at the central site (UTSW) to confirm the diagnosis, and annual on-site audits were conducted by the central site as well.

Definitions. Patients with ALF secondary to acetaminophen toxicity were assigned to one of two groups by the local site investigator, according to the history obtained: intentional (suicidal) ingestion - a single timepoint ingestion in a patient admitting suicidal intent; or unintentional ingestion - a multiple-timepoint ingestion to relieve pain or other somatic symptoms with denial of suicidal intent. Alcohol abuse was defined as consumption of $\geq 40 \mathrm{~g}$ alcohol per day in men and $\geq 20 \mathrm{~g}$ alcohol per day in women. The Acute Physiology and Chronic Health Evaluation (APACHE) II score, Model for End Stage Liver Disease (MELD) score, and the King's College Hospital criteria for ALF ("King's Criteria”) were used to assess overall severity of illness at presentation. ${ }^{17-19}$

Statistical Analysis. Data are presented as medians, ranges, and percentages except where noted. In the analysis of the continuous data, the Student $t$ test or analysis of variance was used. In the analysis of nominal data, the chi-squared test was used to examine differences between groups when there were 2 or more possible values, and Fisher's exact test used if the number of subjects in any group was under 10 . All analyses were two-tailed. $P$ values of less than .05 were considered to indicate statistical significance.

\section{Results}

\section{Overall Study Population}

Of the 662 ALF subjects enrolled during the 6-year study period, $302(46 \%)$ were reported to have acetaminophen-related hepatotoxicity. Twenty-seven were excluded after further review: in 10, the most likely cause was acetaminophen but data were insufficient and no other cause was evident. In 17 patients, competing causes such as viral hepatitis, concomitant polydrug use, or shock were identified. The remaining 275 subjects (42\%) 
constituted the final study group. Over the study period, the percentage of ALF cases attributed to acetaminophen increased from $28 \%$ in 1998 to $51 \%$ in 2003 (Fig. 1). The number and percentage of ALF cases attributed to acetaminophen for the 6-year period far exceeded any other category, with $12 \%$ of cases attributed to idiosyncratic drug-induced hepatotoxicity (prescription drugs, herbs) and 19\% considered indeterminate with no discernible cause after complete evaluation.

\section{Criteria for Diagnosis}

Of the 275 subjects, 155 (56\%) fulfilled the criterion of a history of potentially toxic acetaminophen ingestion, $212(77 \%)$ had detectable acetaminophen levels in serum, and $250(91 \%)$ had ALT $\geq 1,000$ IU/L [ALT was $\geq 3,500 \mathrm{IU} / \mathrm{L}$ in 160 (58\%)]. One hundred eleven (40\%) fulfilled all 3 criteria, 123 subjects (45\%) fulfilled 2 criteria, and 37 subjects (13\%) fulfilled 1 criterion only. In 4 $(1 \%)$, a history of toxic ingestion was reported, but precise data on amount or level of acetaminophen were lacking. However, all 4 of these subjects had elevated ALT levels when they entered the study.

\section{Clinical Presentation}

A total of 242 subjects (88\%) had been transferred from an outlying hospital. Subjects presented a median of 2.0 (range, 1-32) days after the onset of symptoms and had ingested a median total dose of $24 \mathrm{~g}$ (range, 1.2-180 g) of acetaminophen (Table 1). The overall group was predominantly female $(74 \%)$ and white $(88 \%)$. Data on volume of alcohol intake were available in 196 subjects, and $68(35 \% ; 25 \%$ of total group) met criteria for alcohol abuse.

\section{Narcotic and Antidepressant Use}

A total of 147 subjects (53\%) used only over-thecounter (OTC) acetaminophen products; 141 (96\% of this group) consumed only a single OTC product, and 6 $(4 \%)$ used two OTC products. A total of 120 subjects (44\%) reported ingestion of a prescription acetaminophen/narcotic compound (e.g., Vicodin); 76 (28\%) of 275 used these combination products solely, and 41 (15\%) used the prescription combination product with OTC acetaminophen products. One hundred eight subjects $(39 \%)$ reported taking at least one prescription antidepressant, and $34(12 \%)$ reported taking either two or three prescription antidepressants simultaneously. More females used antidepressants ( $46 \%$ vs. $20 \%$ male; $P<$ .0001 ), and antidepressant users were older [median, 39 years (range, 17-64) vs. 34 years (range, 17-76); $P=$ .0018 ], and less likely to use ( $49 \%$ vs. $60 \% ; P=.05)$ or
Table 1. Features of Acetaminophen Overdose ALF Subjects; $\mathrm{N}=\mathbf{2 7 5}$

\begin{tabular}{|c|c|}
\hline Characteristic & Value \\
\hline Age (yrs) & $37(17-76)$ \\
\hline Sex, n (\% female) & $204(74 \%)$ \\
\hline \multicolumn{2}{|l|}{ Race } \\
\hline White & $242(88 \%)$ \\
\hline African American & $15(5 \%)$ \\
\hline Asian & $6(2 \%)$ \\
\hline Hispanic & $5(2 \%)$ \\
\hline Native American & $3(1 \%)$ \\
\hline Other & $4(2 \%)$ \\
\hline \multicolumn{2}{|l|}{ Overdose Type } \\
\hline Unintentional & $131(48 \%)$ \\
\hline Intentional & $122(44 \%)$ \\
\hline Unknown & $22(8 \%)$ \\
\hline Serum acetaminophen level, $\mu \mathrm{g} / \mathrm{dL}(\mathrm{n}=257)$ & $31(0-644)$ \\
\hline Acetaminophen dose, $g(n=179)$ & $24(1.2-180)$ \\
\hline Alcohol use $(n=273)$ & $151(55 \%)$ \\
\hline \multicolumn{2}{|l|}{ Alcohol abuse (male $>40 \mathrm{~g} / \mathrm{d}$; female $>20 \mathrm{~g} / \mathrm{d}$ ) } \\
\hline $\begin{array}{l}\text { Narcotic/acetaminophen compound use ( } n= \\
\text { 267) }\end{array}$ & $120(53 \%)$ \\
\hline \multicolumn{2}{|l|}{ ОтC Acetaminophen Use $(n=147)$} \\
\hline 1 product & $141(51 \%)$ \\
\hline 2 products & $6(2 \%)$ \\
\hline Antidepressant use, n (\%) & $108(61)$ \\
\hline International normalized ratio & $3.0(1.2-27.1)$ \\
\hline Bilirubin, $\mathrm{mg} / \mathrm{dL}^{*}$ & $4.5(0.3-48.2)$ \\
\hline Serum ALT, IU/L & $4,186(136-19,826)$ \\
\hline Serum creatinine, $\mathrm{mg} / \mathrm{dL} \dagger$ & $2.0(0.2-10.5)$ \\
\hline Arterial pH & $7.42(6.94-7.9)$ \\
\hline \multicolumn{2}{|l|}{ Hepatic Coma Grade on admission } \\
\hline 1 & $84(31 \%)$ \\
\hline 2 & $52(19 \%)$ \\
\hline 3 & $63(23 \%)$ \\
\hline 4 & $72(27 \%)$ \\
\hline \multicolumn{2}{|l|}{ Overall outcome } \\
\hline Survived without transplant & $178(65 \%)$ \\
\hline Died without transplant & $74(26 \%)$ \\
\hline Transplantation, lived 3 weeks & $18(6 \%)$ \\
\hline Transplantation; died & $5(2 \%)$ \\
\hline
\end{tabular}

NOTE. Median (range) or numbers (\%) are presented. Abbreviation: OTC, over-the-counter.

*To convert to $\mathrm{mmol} / \mathrm{L}$ multiply by 17.1 .

†To convert to $\mathrm{mmol} / \mathrm{L}$ multiply by 88.4 .

abuse alcohol (24\% vs. $40 \% ; P=.02)$. Those taking antidepressants were also more likely to take additional prescription narcotics $(17 \%$ vs. $5 \% ; P=.003)$ and use acetaminophen/narcotic compound products $(55 \%$ vs. $37 \% ; P=.01)$. Antidepressant use was similar between the groups (37\% vs. $38 \%)$.

\section{Unintentional Versus Intentional Overdose}

A total of 122 subjects (44\%) reported an intentional overdose, and 131 subjects (48\%) experienced an unintentional acetaminophen overdose without suicidal intent (Table 2). In 22 (8\%), the reason for the overdose was unclear. Subjects with unintentional overdose were older 
Table 2. Baseline Features/Outcomes in Intentional and Unintentional Acetaminophen Overdose

\begin{tabular}{|c|c|c|c|c|}
\hline \multirow[b]{2}{*}{ Characteristic } & \multicolumn{2}{|c|}{ Unintentional Overdose $(\mathrm{N}=131)$} & \multicolumn{2}{|c|}{ Intentional Overdose $(\mathrm{N}=122)$} \\
\hline & Value & $\begin{array}{l}\text { No. of Patients } \\
\text { Included }\end{array}$ & Value & $\begin{array}{l}\text { No. of Patients } \\
\text { Included }\end{array}$ \\
\hline Age (years) & $38(18-76)$ & 131 & $34(17-68)$ & 122 \\
\hline Sex $(\%$ female $)$ & $96(73 \%)$ & 131 & $90(74 \%)$ & 122 \\
\hline Survival without transplantation & $84(64 \%)$ & 131 & $80(66 \%)$ & 122 \\
\hline Liver transplantation & $12(9 \%)$ & 131 & $8(7 \%)$ & 122 \\
\hline Listed for liver transplantation & $35(27 \%)$ & 130 & $30(25 \%)$ & 122 \\
\hline \multicolumn{5}{|l|}{ Days from admission to } \\
\hline \multicolumn{5}{|l|}{ Overall short-term (3-week) } \\
\hline survival & $94(72 \%)$ & 131 & $87(71 \%)$ & 122 \\
\hline NAC treatment given & $125(95 \%)$ & 131 & $106(87 \%)$ & 122 \\
\hline Cause of pain reported* & $107(81 \%)$ & 116 & $0(0 \%)$ & 122 \\
\hline Total acetaminophen dose (g) & $20(2.5-180)$ & 81 & $25(1.2-90)$ & 91 \\
\hline Daily acetaminophen dose (g) & $7.5(1.0-78)$ & 77 & $25(1.2-90)$ & 91 \\
\hline Serum acetaminophen $(\mu \mathrm{g} / \mathrm{dL})$ & $18(0-400)$ & 119 & $64(0-644)$ & 118 \\
\hline Narcotic/acetaminophen use & $83(63 \%)$ & 131 & $22(18 \%)$ & 122 \\
\hline Antidepressant use & $48(37 \%)$ & 131 & $46(38 \%)$ & 122 \\
\hline Serum ALT (U/L) & $3,319(126-18,079)$ & 130 & $5,326(179-19,826)$ & 122 \\
\hline Platelets (thousands/ $\mu \mathrm{L}$ ) & $126(15-699)$ & 131 & $120(5-447)$ & 120 \\
\hline Admission Hepatic Coma stage & $3(1-4)$ & 131 & $2(1-4)$ & 118 \\
\hline \multicolumn{5}{|l|}{ Admission Hepatic Coma } \\
\hline (stages 3-4) & $72(55 \%)$ & 131 & 47 (39\%) & 122 \\
\hline Peak hepatic coma stage & $3(1-4)$ & 131 & $3(1-4)$ & 120 \\
\hline \multicolumn{5}{|l|}{ Peak hepatic coma (stages } \\
\hline $3-4)$ & $89(68 \%)$ & 131 & 72 (59\%) & 122 \\
\hline Met King's criteria & $26(20 \%)$ & 131 & $8(7 \%)$ & 122 \\
\hline Creatinine $\geq 2$ & $74(57 \%)$ & 131 & $53(43 \%)$ & 122 \\
\hline INR $\geq 3$ & $56(42 \%)$ & 131 & $68(56 \%)$ & 122 \\
\hline $\mathrm{ALT} \geq 3,500$ & $63(48 \%)$ & 131 & $88(72 \%)$ & 122 \\
\hline Bilirubin $\geq 4$ & $73(56 \%)$ & 131 & $74(61 \%)$ & 122 \\
\hline MELD $\geq 20$ & $113(88 \%)$ & 129 & $102(87 \%)$ & 117 \\
\hline APACHE $\| \geq 15$ & $75(66 \%)$ & 113 & $49(57 \%)$ & 86 \\
\hline BMI & $25(17-51)$ & 97 & $24(16-56)$ & 99 \\
\hline
\end{tabular}

NOTE. Median (range) or numbers (\%) are presented. 22 subjects could not be classified as suicidal or accidental. Data available for all 275 subjects except as noted $(n=x x)$.

*Reported causes of pain: chronic pain $(n=33)$, chronic back pain $(n=24)$, headache $(n=14)$, chronic abdominal pain $(n=9)$, viral URI $(n=7)$, migraine $(n=9)$, toothache $(n=6)$, orthopedic pain $(n=5)$, fibromyalgia $(n=4)$, rheumatologic pain $(n=5)$, chronic pancreatitis $(n=2)$; postsurgical pain $(n=2)$, and one each: hangover, earache, fever, menstrual pain; insomnia, leg pain.

(median, 38 years [range, 18-76]) than those who attempted suicide (median, 32 years [range, 17-68]; $P=$ .002 ), used multiple acetaminophen-containing preparations more frequently $(38 \%$ vs. $5 \% ; P<.0001)$, and sought care longer after symptom onset (median 4 days vs. 1 day). Unintentional overdose patients were less likely to report depression ( $24 \%$ vs. $45 \% ; P=.001)$. This group had significantly lower serum acetaminophen levels (16 $\mu \mathrm{g} / \mathrm{dL}$ [range, $0-400$ ] vs. $84 \mu \mathrm{g} / \mathrm{dL}[0-644] ; P<.0001)$ and lower ALT levels $(3,319$ IU/L [range, 126-18,079] vs. 5,326 IU/L [179-19,826]; $P<.0001)$ at the time of admission to study. Unintentional patients were more likely to have severe (grades 3 and 4) hepatic encephalopathy on admission compared with the intentional overdose group ( $55 \%$ vs. $39 \% ; P=.002$ ); however, the peak hepatic encephalopathy grade achieved during the course of hospitalization and the number listed for transplanta- tion and time to transplantation did not differ between the groups. No other clinical features differed between the 2 groups. History of past substance abuse was similar between groups (unintentional, $35 \%$ vs. intentional, $31 \% ; P=.11$ ). Toxicology screens (all drugs of abuse, including narcotics) were available in 77 subjects $(28 \%)$ and positive in 58 (21\%). Among the 58 with positive screens were 10 positive for marijuana, 11 for cocaine, and 5 for amphetamines. The remainder were positive for opiates, benzodiazepines, barbiturates, or tricyclic antidepressants or combinations thereof, most of which likely represented prescribed medications. The educational level was similar between the unintentional (mean, 12.97 years) and intentional (13.26 years) groups, and these were similar to that seen in the ALF patients as a whole (13.22 years) and to those with drug-induced liver injury from other causes (13.53 years). 


\section{Unintentional Overdose Patients: > 7 Day Group}

Nineteen patients with unintentional overdose reported that they had used acetaminophen for more than 7 days. This chronic use group was older, weighed more, reported larger total acetaminophen ingested, was more likely to report pain as the reason for use, was less likely to use alcohol, and was more likely to take additional narcotics. This group otherwise did not differ from those who used acetaminophen for fewer than 7 days in any other measurement.

\section{Prescription Acetaminophen/Narcotic Compound Use}

Use of prescription narcotic/acetaminophen compounds ("compounds") was reported by 120 (44\%) of the entire group of patients studied and was primarily observed in the unintentional group $(63 \%$ vs. $18 \%$ for the intentional group; $P<.0001)$. The product most commonly used was Vicodin (acetaminophen/hydrocodone, Abbott Laboratories, Chicago IL; $\mathrm{n}=83$ of 120). Clinical indicators of disease severity such as platelets, serum ALT, and bilirubin were significantly lower in the compound users. However, other indicators, including transplantation rate and overall survival, did not differ between the compound users and remaining subjects.

\section{Alcohol Use and Abuse}

Those who chronically used or abused alcohol constituted $55 \%$ and $35 \%$, respectively, of the entire group. Compared with nonabusers, alcohol abusers had lower acetaminophen levels $(15 \mu \mathrm{g} / \mathrm{dL}$ [range, $0-315]$ vs. 34 $\mu \mathrm{g} / \mathrm{dL}[0-644] ; P=.003)$, were less likely to use antidepressants $(24 \%$ vs. $40 \% ; P=.03)$ or compound narcotics (31\% vs. $50 \% ; P=.009)$, and were less likely to present with severe (grades 3 and 4 ) hepatic encephalopathy $(34 \%$ vs. $53 \% ; P=.02)$. Clinically, there were no other differences between those who were abstinent and those who abused alcohol with regard to INR, ALT, bilirubin, body mass index (BMI), APACHE II score, MELD score, or overall survival (data not shown).

\section{Ingestion of Low Doses of Acetaminophen: $\leq 4$ Grams/Day}

Nineteen $(7 \%)$ subjects reported taking $\leq 4 \mathrm{~g}$ acetaminophen per day before presentation. Sixteen had ALT levels over 1,000 IU/L (range for the entire group: 13611,240), and 12 had measurable serum acetaminophen levels. Compared with the remaining subjects ingesting higher doses, the low-dose group was older (median, 46 vs. 34 years; $P=.01$ ), more often reported unintentional overdose (74\% vs. $40 \% ; P<.002)$, and more often used (79\% vs. $59 \% ; P=.09)$ or abused $(65 \%$ vs. $37 \% ; P=$
.02) alcohol. The low-dose group displayed slightly lower serum acetaminophen levels (median, $14.5 \mu \mathrm{g} / \mathrm{dL}$ [range, $0-383]$ vs. $31 \mu \mathrm{g} / \mathrm{dL}$ [0-315]) and elevations in serum ALT (median, 2,949 IU/L [range 175-19,826] vs. 4,224 IU/L [136-11,240]); however, these differences were not statistically significant. All other measures were similar between the low- and higher-dose groups.

\section{Outcome and Predictors of Spontaneous Survival}

Overall, 178 subjects (65\%) survived without liver transplantation; $74(27 \%)$ died, and 23 subjects (8\%) underwent transplantation. Seventy-two subjects (26\%) were listed for transplantation: 20 died and 29 recovered without receiving an organ. Overall, 196 subjects (71\%) were reported to be alive at the 3 -week outcome point.

Spontaneous Survival. The 178 nontransplanted survivors were less ill at presentation than the nonsurvivors (Table 3). Although spontaneous survivors were more likely to have abused alcohol, there were no significant differences in sex, age, ethnicity, type of overdose, total acetaminophen dose, serum acetaminophen level, antidepressant use, narcotic or narcotic compound use, bilirubin, platelets, temperature, or BMI at presentation between the groups (data not shown).

Use of King's Criteria. The King's criteria for liver transplantation were fulfilled on admission in only 40 subjects, of whom 19 died without transplant and 6 underwent transplantation (2 died and 4 were alive at 3 weeks). ${ }^{18}$ Of 235 subjects who did not meet the King's criteria, 163 subjects survived without a transplant, 55 died without receiving a transplant, and 17 subjects underwent liver transplantation (3 of whom died and 14 were alive at the 3-week outcome timepoint), yielding a low sensitivity and high specificity (Table 4).

Use of the APACHE II Score. The APACHE II score assessing overall severity of illness on admission was available in 216 subjects and was divided into 2 groups (low at $<20$ and high at $\geq 20$ ), based on a receiver operator characteristic curve (data not shown). ${ }^{17}$ Subjects with an APACHE II score of $\geq 20$ had a significantly lower transplant-free survival than subjects with a score of $<20$ (43\% vs. 92\%, $P<.0001$ ) and more often underwent transplantation $(13 \%$ vs. $1 \% ; P=.002)$; this yielded a much higher sensitivity but slightly lower specificity than the King's criteria (Table 4).

\section{Discussion}

Acetaminophen poisoning has become the most common cause of ALF in both the United States and the United Kingdom. ${ }^{13,20-22}$ Underreporting may have occurred in the past when transplant databases were used. ${ }^{13,22}$ Nevertheless, current data suggest a dramatic 
Table 3. Comparison of Spontaneous Survivors and Nonsurvivors (Death or Transplant)

\begin{tabular}{|c|c|c|c|}
\hline Characteristic & $\begin{array}{l}\text { Died or Transplantation } \\
\qquad(\mathrm{N}=97)\end{array}$ & $\begin{array}{l}\text { Survival Without Transplantation ( } \mathrm{N} \\
=178 \text { ) }\end{array}$ & $P$ Value \\
\hline Age (years) & $38(18-76)$ & $36(17-68)$ & .68 \\
\hline Chronic alcohol use $(n=273)$ & $48(50 \%)$ & 103 (58\%) & .21 \\
\hline Chronic alcohol abuse $(n=196)$ & $15(24 \%)$ & 53 (39\%) & .04 \\
\hline NAC treatment received & $90(93 \%)$ & $162(91 \%)$ & .82 \\
\hline Admission hepatic coma grade $(n=271)$ & $4(1-4)$ & $2(1-4)$ & $<.0001$ \\
\hline Admission hepatic coma (stages 3-4) & $75(77 \%)$ & $60(34 \%)$ & $<.0001$ \\
\hline Peak hepatic coma grade $(n=273)$ & $4(1-4)$ & $2(1-4)$ & $<.0001$ \\
\hline Peak hepatic coma (stages 3-4) & $96(99 \%)$ & $84(47 \%)$ & $<.0001$ \\
\hline Met Kings criteria (\% yes) & $25(26 \%)$ & $15(8 \%)$ & $<.0001$ \\
\hline APACHE II score $(n=216)$ & $22.5(8-40)$ & $14(2-31)$ & $<.0001$ \\
\hline Apache II score >15 (\% yes) & $78(93 \%)$ & $60(45 \%)$ & $<.0001$ \\
\hline MELD score $(n=268)$ & $36(11-53)$ & $28(7-52)$ & $<.0001$ \\
\hline Systolic blood pressure $(n=274)$ & $117(64-188)$ & $129(77-191)$ & .005 \\
\hline Heart rate (beats per minute) $(n=273)$ & $116(65-156)$ & $99(53-145)$ & $<.0001$ \\
\hline White blood cells (thousands) $(n=273)$ & $12.4(1.6-49.8)$ & $9.1(1.4-25.6)$ & .0002 \\
\hline INR $(n=269)$ & $3.8(1.3-27.1)$ & $2.8(1.2-24.1)$ & .004 \\
\hline $\operatorname{ALT}(\mathrm{n}=274)$ & $4,429(136-19,826)$ & $4,030(158-15,120)$ & .05 \\
\hline Creatinine & $2.7(0.2-9.2)$ & $1.4(0.4-10.5)$ & .0003 \\
\hline Arterial $\mathrm{pH}(\mathrm{n}=246)$ & $7.38(6.94-7.67)$ & $7.44(7.0-7.9)$ & .01 \\
\hline
\end{tabular}

NOTE. Median (range) or numbers (\%) are presented. Data were available for all 275 subjects except as noted $(n=x x x)$.

increase in acetaminophen toxicity recently; the percentage of all ALF cases in our registry that were due to acetaminophen has nearly doubled in 6 years. Although they are less frequent in terms of overall acetaminophen-related hospitalizations, unintentional overdoses constitute at least half of all those that develop encephalopathy. ${ }^{7}$ Intentional and unintentional cases have similar clinical pictures and outcomes once the threshold of ALF has been reached. In many subjects, multiple factors appear to be at play, including repeated dosing in excess of package labeling, use of multiple acetaminophen-containing products, simultaneous use/abuse of alcohol and narcotics, and depression. Patients with chronic pain appear to be particularly susceptible to this problem.

Although our study included consecutive subjects studied prospectively, it has several limitations. First, we portray here only the most severely ill subjects who meet criteria for ALF. ${ }^{7}$ In addition, our group may not represent the true incidence of ALF in the population at large, because many patients are not referred to transplant centers because of failure to diagnose ALF, presumption of mild disease, suicide or substance abuse histories, poor prognosis (cancer patients, the elderly), or unsuitability for liver transplantation. ${ }^{14}$ Our patients were evaluated by experienced hepatologists, and the history of all drug and alcohol ingestion was determined carefully. Nevertheless, patients by definition have altered mentation, making accurate history-taking difficult or impossible. For example, obtaining a recent food or alcohol intake history immediately before hospitalization was not feasible. More than $80 \%$ of patients were transferred from other institutions, often after significant encephalopathy had set in, compromising history (i.e., time of last dose, total dose ingested, etc.).

Our study sites, representing approximately 30\% of U.S. transplant capability (United Network for Organ Sharing data), recorded an average of 49 acetaminophenrelated liver failure cases/year over the 6-year period. Based on data from site enrollment logs, an additional $40 \%$ of cases were not enrolled because of lack of informed consent or inadequate information to ensure the diagnosis (data not shown). Thus, we estimate that at least 250 cases of acetaminophen-related ALF are seen annually at U.S. transplant centers, resulting in approximately 73 deaths. This is considerably less than the estimated 458 deaths per year attributable to acetaminophen poisoning predicted by the FDA, possibly reflecting lack of referral for transplant of suicidal or substance-abuse patients. Nevertheless, a high proportion of our patients who were referred to a transplant center demonstrated substance

Table 4. Comparison of Sensitivity, Specificity, and Positive and Negative Predictive Values of Two Prognostic Systems

\begin{tabular}{|c|c|c|c|c|c|c|}
\hline & Sensitivity & Specificity & $\begin{array}{c}\text { Positive } \\
\text { Predictive Value }\end{array}$ & $\begin{array}{c}\text { Negative } \\
\text { Predictive Value }\end{array}$ & Percent Correct & $\begin{array}{l}\text { Likelihood } \\
\text { Ratio }\end{array}$ \\
\hline Kings $(\geq 1)$ & $26 \%$ & $92 \%$ & $63 \%$ & $69 \%$ & $68 \%$ & 3.06 \\
\hline APACHE $\|(\geq 20)$ & $68 \%$ & $87 \%$ & $77 \%$ & $81 \%$ & $80 \%$ & 5.27 \\
\hline
\end{tabular}


abuse or major psychiatric problems. Of interest, data from a large national survey suggest that $36 \%$ of Americans ingest an acetaminophen-containing compound at least once a month; this figure underscores the low incidence of ALF due to acetaminophen overdose compared with the millions of tablets consumed on a daily basis. ${ }^{23}$

One of the most alarming findings in our study was that unintentional acetaminophen overdose accounted for $50 \%$ of our cases. The rate of unintentional overdose was estimated to be $31 \%$ in Australia, and nonsuicidal overdoses are only rarely reported in the United Kingdom and Europe. ${ }^{24-26}$ Single timepoint ingestions with suicidal intent constituted $70 \%$ of all hospitalized subjects in one U.S. series, but these subjects frequently presented early after ingestion when use of NAC would be effective, so that few developed encephalopathy and only $2 \%$ died. ${ }^{7}$ In the current series, in which cases were limited to those subjects reaching the threshold of encephalopathy, the mortality rate was higher (approximately 29\%) and similar for the intentional and unintentional groups. Whereas unintentional cases uniformly present after symptoms have developed, those with suicidal intent who develop encephalopathy typically have other cofactors such as use of alcohol, narcotics, or sedatives that may delay presentation or enhance toxicity.

We have been careful to describe the features of the unintentional group because their incidence differs markedly from the experience in other countries. Amongst unintentional overdose patients, most $(79 \%)$ reported that they were taking the medication(s) specifically for pain or constitutional symptoms (8\%). Many claimed to have ingested modest amounts of acetaminophen over weeks or months, with $63 \%$ reporting use of narcotic combinations. ${ }^{4,6,27-29}$ Why, then, the sudden onset of severe liver injury? Our data suggest that there is a narrow therapeutic margin and that consistent use of as little as $7.5 \mathrm{~g} /$ day may be hazardous. However, precise information on dosing is often difficult to acquire in some of these patients. We are planning to look at this issue in more detail in a future study. Late presentation is undoubtedly a factor in the unintentional cases as described in this study and previously, ${ }^{7}$ but the acuity of the unintentional cases (height of ALT levels, severity of illness) was similar to single timepoint ingestions. The development of tolerance to gradually increasing doses of acetaminophen has been reported previously in association with narcotic abuse. ${ }^{27}$ Worsening pain may occasion the supra-normal dosing in the days before admission. Alternatively, loss of tolerance may result from alcohol use, starvation, or inter-current illness leading to glutathione depletion. ${ }^{6}$ In spite of longterm ingestion histories, the cases that reported $>7$ days' ingestion still had an acute injury, in terms of their bio- chemical values, that was indistinguishable from suicidal ingestions, suggesting that there is no chronic form of injury, but rather a threshold of safety that may be breached with devastating results. Toxicological testing, while performed in a limited number of patients, strongly suggested use of illicit drugs, although the information available included illegal as well as legal narcotic use. There was no impact observed for lower socioeconomic groups in the acetaminophen group because no difference in level of education was evident between the acetaminophen groups and other forms of ALF. Some may have had genetic polymorphisms making them more susceptible to acetaminophen poisoning at lower doses, but most had ingested doses that would be expected to cause severe liver injury. ${ }^{30,31}$

A second potential reason for toxicity is the simultaneous use of 2 preparations, recorded in $22 \%$ overall, and $38 \%$ of the unintentional group. Information was not available regarding the reason for the use of 2 preparations, but frustration, impulsivity, or simply lack of recognition of the presence of acetaminophen in both preparations have all been recognized. ${ }^{32}$ Of interest, a third of narcotic users were simultaneously ingesting an over-the-counter acetaminophen product (data not shown). This suggests patients' lack of awareness of the hazards of over-the-counter acetaminophen use in combination with prescribed agents. ${ }^{32} \mathrm{An}$ independent interview evaluation after patients have recovered might help in establishing exact dosages, reasons for excess ingestion, and patient understanding of the implications of overdosing on this ubiquitous but hazardous medication. ${ }^{33}$

A full third of our subjects met standard criteria for alcohol abuse (i.e., $>40 \mathrm{~g} /$ day in men and $>20 \mathrm{~g} /$ day in women). These subjects less often used acetaminophen/ narcotic compounds or antidepressants, suggesting that they may have been self-medicating with alcohol. Their acetaminophen levels were lower, despite reporting intake of similar amounts of acetaminophen. Because the subjects with ALF reporting use of $\leq 4 \mathrm{~g}$ acetaminophen per day were often alcohol abusers (65\%) and the amount of daily alcohol consumed was greater than that reported by patients who admitted to taking $>4 \mathrm{~g}$ acetaminophen per day (data not shown), ethanol may still serve as an important co-factor in these lower-dose subjects. ${ }^{4,6,13,24,34-36}$

The overall transplant-free survival rate of $65 \%$ in acetaminophen subjects is comparable to that of prior studies and continues to be more favorable than that observed for most other ALF causes. ${ }^{13,37,38,39}$ The use of the King's criteria at admission to predict outcome was inaccurate, and use of the APACHE II provided a more accurate of assessment outcome. Clearly, improved prognostic criteria are needed. $22,39,40$ 
In conclusion, acetaminophen poisoning now accounts for at least $42 \%$ of U.S. acute liver failure cases seen at tertiary-care centers and one third of the deaths. Unintentional overdose is the leading form of acetaminophen hepatotoxicity in U.S. ALF subjects, but suicidal ingestions remain important as well. Susceptible patients include those with chronic pain, depression, and substance abuse, including alcohol. Legislative changes in the United Kingdom leading to restrictions in the sales of acetaminophen have reduced the number of patients dying from or needing transplantation because of acetaminophen hepatotoxicity. ${ }^{33,41-46}$ Because most cases in the United Kingdom are considered to be suicidal, they differ in that sense from unintentional cases. Nevertheless, efforts to limit OTC package size and to restrict the prescription of narcotic-acetaminophen combinations (or to separate the narcotic from the acetaminophen) may be necessary to reduce the incidence of this increasingly recognized but preventable cause of ALF in the United States. Educational programs for practicing physicians, pharmacists, and consumers, involving a full discussion of the hazards of this ubiquitous pain reliever and the identification of susceptible groups, seems warranted.

Acknowledgment: The authors thank all the nurses, investigators, and house staff who tirelessly work to make this study possible.

\section{Appendix}

The Acute Liver Failure Study Group 1998-2003:

William M. Lee (PI), Julie Polson, Ezmina Lalani, Frank V. Schiødt, George Ostapowicz, Linda S. Hynan, Joan S. Reisch, University of Texas Southwestern Medical Center, Dallas, TX

Anne M. Larson, Hao Do, University of Washington, Seattle, WA Jeffrey S. Crippin, Laura Gerstle, Washington University School of Medicine, St. Louis, MO

Timothy J. Davern, Nathan Bass, Lily Luu, University of California at San Francisco, CA

Michael Schilsky, Jeanna Zalsos, Mt Sinai Medical Center, New York, NY

Timothy M. McCashland, Tamara Bernard, University of Nebraska, Omaha, NE

J. Eileen Hay, Cindy Groettum, Mayo Clinic, Rochester, MN

Natalie Murray, Sonnya Coultrup, Baylor University Medical Center, Dallas, TX

A. Obaid Shakil, Diane Morton, University of Pittsburgh Medical Center, Pittsburgh, PA

Andres T. Blei, Jeanne Gottstein, Northwestern University Medical School, Chicago, IL

Atif Zaman, Renee Rutledge, Oregon Health Sciences University, Portland, OR CA

Steven Han, Val Peacock, University of California at Los Angeles,

Robert J. Fontana, Nadia Tayeh, University of Michigan Medical Center, Ann Arbor, MI

Brendan McGuire, Pam Davis, University of Alabama, Birmingham, AL

Raymond Chung, Deborah Casson, Massachusetts General Hospital, Boston, MA
Robert Brown Jr., Laren Senkbeil, Columbia-Presbyterian Medical Center, New York, NY

M. Edwyn Harrison, Rebecca Rush, Mayo Clinic, Scottsdale, AZ Adrian Reuben, Nancy Huntley, Medical University of South Carolina, Charleston, SC

Santiago Munoz, Chandra Misra, Albert Einstein Medical Center, Philadelphia, PA

Todd Stravitz, Jennifer Salvatori, Virginia Commonwealth University, Richmond, VA

Lorenzo Rossaro, Katherine Suggett, University of California, Davis; Sacramento, CA

Raj Satyanarayana, Wendy Taylor, Mayo Clinic, Jacksonville, FL

\section{References}

1. Black M. Acetaminophen hepatotoxicity. Annu Rev Med 1984;35:577593.

2. Davidson DG, Eastham WN. Acute liver necrosis following overdose of paracetamol. Br Med J 1966;5512:497-499.

3. Thomson JS, Prescott LF. Liver damage and impaired glucose tolerance after paracetamol overdosage. Br Med J 1966;5512:506-507.

4. Zimmerman HJ, Maddrey WC. Acetaminophen (paracetamol) hepatotoxicity with regular intake of alcohol: analysis of instances of therapeutic misadventure. HEPATOLOGY 1995;22:767-773.

5. Maddrey WC. Hepatic effects of acetaminophen. Enhanced toxicity in alcoholics. J Clin Gastroenterol 1987;9:180-185.

6. Whitcomb DC, Block GD. Association of acetaminophen hepatotoxicity with fasting and ethanol use. JAMA 1994;272:1845-1850.

7. Schiodt FV, Rochling FA, Casey DL, Lee WM. Acetaminophen toxicity in an urban county hospital N Engl J Med 1997;337:1112-1117.

8. Rumack BH. Acetaminophen misconceptions. HePATOLOGY 2004;40:1015.

9. Vale JA, Proudfoot AT. Paracetamol (acetaminophen) poisoning. Lancet 1995;346:547-552.

10. Schiodt FV, Bondesen S, Tygstrup N, Christensen E. Prediction of hepatic encephalopathy in paracetamol overdose: a prospective and validated study. Scand J Gastroenterol 1999;34:723-728.

11. Ritt DJ, Whelan G, Werner DJ, Eigenbrodt EH, Schenker S, Combes B. Acute hepatic necrosis with stupor or coma. An analysis of thirty-one patients. Medicine (Baltimore) 1969;48:151-172.

12. Rakela J, Perkins JD, Gross JB, Jr, Hayes DH, Plevak DJ, Krom RA, et al. Acute hepatic failure: the emerging role of orthotopic liver transplantation. Mayo Clin Proc 1989;64:424-428.

13. Schiodt FV, Atillasoy E, Shakil AO, Schiff ER, Caldwell C, Kowdley KV, et al. Etiology and outcome for 295 patients with acute liver failure in the United States. Liver Transpl Surg 1999;5:29-34.

14. Quallich LG, Shehab TM, Brown JW, Fontana RJ. Management of Acetaminophen Hepatotoxicity: A Survey of Practicing Physicians. J Clin Outcomes Management 2001:25-32.

15. Trey C, Davidson CS. The management of fulminant hepatic failure. In: Popper H, Schaffner F, eds. Progress in Liver Diseases. New York: Grune \& Stratton, 1970:282-292.

16. Ostapowicz G, Fontana RJ, Schiodt FV, Larson A, Davern TJ, Han SH, et al. Results of a prospective study of acute liver failure at 17 tertiary care centers in the United States. Ann Intern Med 2002;137:947-954.

17. Knaus WA, Draper EA, Wagner DP, Zimmerman JE. APACHE II: a severity of disease classification system. Crit Care Med 1985;13:818-829.

18. O'Grady JG, Alexander GJ, Hayllar KM, Williams R. Early indicators of prognosis in fulminant hepatic failure. Gastroenterology 1989;97:439445.

19. Kamath PS, Wiesner RH, Malinchoc M, Kremers W, Therneau TM, Kosberg CL, et al. A model to predict survival in patients with end-stage liver disease. Hepatology 2001;33:464-470.

20. Williams R, Wendon J. Indications for orthotopic liver transplantation in fulminant liver failure. HePATOLOGY 1994;20:S5-10S.

21. Makin AJ, Williams R. Acetaminophen-induced hepatotoxicity: predisposing factors and treatments. Adv Intern Med 1997;42:453-483. 
22. Shakil AO, Kramer D, Mazariegos GV, Fung JJ, Rakela J. Acute liver failure: clinical features, outcome analysis, and applicability of prognostic criteria. Liver Transpl 2000;6:163-169.

23. US Department of Health and Human Services (DHHS). Third National Health and Nutrition Examination Survey, 1988-1994, NHANES III Second Laboratory Data File. (CD-ROM, Series 11, No 2A). Hyattsville, MD: Centers for Disease Control and Prevention, 1998.

24. Makin A, Williams R. Paracetamol hepatotoxicity and alcohol consumption in deliberate and accidental overdose. Q J Med 2000;93:341-349.

25. Larsen FS, Kirkegaard P, Rasmussen A, Hansen BA. The Danish liver transplantation program and patients with serious acetaminophen intoxication. Transplant Proc 1995;27:3519-3520.

26. Gow PJ, Jones RM, Dobson JL, Angus PW. Etiology and outcome of fulminant hepatic failure managed at an Australian liver transplant unit. J Gastroenterol Hepatol 2004;19:154-159.

27. Shayiq RM, Roberts DW, Rothstein K, Snawder JE, Benson W, Ma X, et al. Repeat exposure to incremental doses of acetaminophen provides protection against acetaminophen-induced lethality in mice: an explanation for high acetaminophen dosage in humans without hepatic injury. HEPATOLOGY 1999;29:451-463.

28. Csete M, Sullivan JB. Vicodin-induced fulminant hepatic failure. Anesthesiology 1993;79:857-860.

29. Block R, Jankowski JA, Lacoux P, Pennington CR. Does hypothermia protect against the development of hepatitis in paracetamol overdose? Anaesthesia 1992;47:789-791.

30. Court MH, Duan SX, Von Moltke LL, Greenblatt DJ, Patten CJ, Miners $\mathrm{JO}$, et al. Interindividual variability in acetaminophen glucuronidation by human liver microsomes: identification of relevant acetaminophen UDPglucuronosyltransferase isoforms. J Pharmacol Exp Ther 2001;299:9981006.

31. Acuna G, Foernzler D, Leong D, Rabbia M, Smit R, Dorflinger E, et al. Pharmacogenetic analysis of adverse drug effect reveals genetic variant for susceptibility to liver toxicity. Pharmacogenomics J 2002;2:327-334.

32. Chen L, Schneider S, Wax P. Knowledge about acetaminophen toxicity among emergency department visitors. Vet Hum Toxicol 2002;44:370373.

33. Hawton K, Townsend E, Deeks J, Appleby L, Gunnell D, Bennewith O, et al. Effects of legislation restricting pack sizes of paracetamol and salicylate on self poisoning in the United Kingdom: before and after study. BM] 2001;322:1203-1207.
34. Schmidt LE, Dalhoff K, Poulsen HE. Acute versus chronic alcohol consumption in acetaminophen-induced hepatotoxicity. Hepatology 2002; 35:876-882.

35. Thummel KE, Slattery JT, Ro H, Chien JY, Nelson SD, Lown KE, et al. Ethanol and production of the hepatotoxic metabolite of acetaminophen in healthy adults. Clin Pharmacol Ther 2000;67:591-599.

36. Prescott LF. Paracetamol, alcohol and the liver. Br J Clin Pharmacol 2000; 49:291-301.

37. Williams R. Classification, etiology, and considerations of outcome in acute liver failure. Semin Liver Dis 1996;16:343-348.

38. Schiodt FV, Lee WM. Management of acetaminophen toxicity. In: Krawitt E, ed. Medical Management of Liver Disease. New York: Marcel Dekker, 1999:325-337.

39. Pauwels A, Mostefa-Kara N, Florent C, Levy VG. Emergency liver transplantation for acute liver failure: evaluation of London and Clichy criteria. J Hepatol 1993;17:124-127.

40. Mitchell I, Bihari D, Chang R, Wendon J, Williams R. Earlier identification of patients at risk from acetaminophen-induced acute liver failure. Crit Care Med 1998;26:279-284.

41. Bernal W. Changing patterns of causation and the use of transplantation in the United kingdom. Semin Liver Dis 2003;23:227-237.

42. Wilkinson S, Taylor G, Templeton L, Mistral W, Salter E, Bennett P. Admissions to hospital for deliberate self-harm in England 1995-2000: an analysis of hospital episode statistics. J Public Health Med 2002;24:179183.

43. Gunnell D, Hawton K, Murray V, Garnier R, Bismuth C, Fagg J, et al. Use of paracetamol for suicide and non-fatal poisoning in the UK and France: are restrictions on availability justified? J Epidemiol Community Health 1997;51:175-179.

44. Sheen CL, Dillon JF, Bateman DN, Simpson KJ, MacDonald TM. Paracetamol pack size restriction: the impact on paracetamol poisoning and the over-the-counter supply of paracetamol, aspirin and ibuprofen. Pharmacoepidemiol Drug Saf 2002;11:329-331.

45. Robinson D, Smith AM, Johnston GD. Severity of overdose after restriction of paracetamol availability: retrospective study. BMJ 2000;321:926927.

46. Hawton K, Simkin S, Deeks J, Cooper J, Johnston A, Waters K, et al. UK legislation on analgesic packs: before and after study of long term effect on poisonings. BMJ 2004;329:1076. 